\title{
THE ENERGY CONSUMPTIONS AND ENVIRONMENTAL POLLUTION OF STRATIFIED CHARGE AND CONVENTIONAL SPARK IGNITION ENGINES
}

\author{
HAMDY.M.NOUR
}

\begin{abstract}
The consumed fuel energy, and the emission of exhaust gasses of stratified charge, and conventional spark ignition engines were investigated and evaluated. The comparative tests were deduced under numerous variables included the injected fuel types, compression and charge volume ratio, degree of charge stratification, engine speeds, and the time of injection.

The obtained results revealed that, replacing the stratified charge ignition engines(SCIE) instead of the conventional ignition engines(CIE), can be rationalized the energy consumption, and reduced the environmental pollution associated with the applications of stationary power sources in the Egyptian farms. Whereas, the (SCIE) engine yields reduction in NO emissions in the range of.4.21: 7.0\% It is also decreased the specific fuel consumption (SFC) in the range of.8.7: 9.94\% compared with the conventional injection engines(CIE).

In addition the (SCIE) engine can be operated by injecting different fuels at high compression ratios and at lean mixture without combustion problems which in turn leads to increase the thermal efficiency,

Injection of oxygen in the beginning of compression stroke enhances the engine performance and Combustion characteristics.

Stratified charge engines can be operated by injecting different fuels at high compression ratios and at lean mixture without combustion problems which in turn leads to increasing the thermal efficiency, and leads to the decrease of NO concentration emitted with the exhaust products.
\end{abstract}


Stratified charge engines can be operated at lean mixture until an equivalence ratio of 0.55 , which couldn't be achieved with the conventional engines. The operation with lean mixture leads to the decrease of NO concentration emitted with the exhaust products.

\section{INTRODUCTION}

7 hese environmental problems affecting human and animal health and other green areas.

1 The conventional four stroke cycle spark ignition engine continues to be used extensively in many fields and is expected to serve as a power source in automobiles for many years to come. Engine fuel contemplation as well as environmental pollution, fuel consumption and exhaust emission are very important factors in engine performance. As well established, the keys for enhancing thermal efficiency are to operate engines at higher compression ratios and weaker mixtures especially at part loads. The technical problems with the former are these avoiding "Knock" at high compression ratios. A number of concepts for the operation of lean burning engines, such as torch ignition and stratified charge combustion, have been proposed. In such a stratified charge engine, arrangements are made for the generation of a slightly fuel rich region mixture in the vicinity of the spark plug, whilst the overall air-fuel ratio is maintained lean.

An internal-combustion engine with a divided ignition cylinder that uses the ignition of rich fuel in a small chamber near the spark plug to improve the combustion of a very lean mixture throughout the rest of the cylinder (Choi, S. B., and Hedrick, J. K., 2000).

Pr-chamber injected type of divided chamber engine has been studied by (Nakazono,1994) also (Nakazono and Natsumi, 1994), they investigated the effect of dimensions of pre-chamber on lean burn gas engine. They concluded that, it is necessary to control air/fuel ratio (AFR) more finely and optimize the shape of mainchamber and the hole dimensions in order to improve the thermal efficiency while decreasing No emission.

More importantly, air/fuel ratio( AFR) also influences the effect of emission control because its stoichiometric value ensures the 
maximum efficiency of three-way catalysts(TWC). AFR variations of greater than $1 \%$ below 14.7 will result in a

Significant increase of $\mathrm{CO}$ and $\mathrm{HC}$ emissions, while an increase of more than $1 \%$ will produce more NOx up to 50\%(Manzie, C., Palaniswami, M., and Watson, H., 2001) and (Manzie, C., Palaniswami, M., Ralph, D.and Watson, H. 2002) When operating in stratified charge combustion mode, they are very different from conventional stoichiometric engines, creating new opportunities for improved speed control. With current aftertreatment technology, simultaneous high fuel economy and emissions conversion efficiency cannot be achieved by operating the engine in a steady-state manner: it must be cycled between running ultra-lean (for fuel economy) and rich (to service the aftertreatment system) (Grizzle.J.W,Julia Buckland and Jing Sun 2001). The aim of the present study is to investigate and compare the brake effective pressure characteristic and exhaust emission, of the stratified charge, and the conventional spark ignition engines. The obtained data may be helpful to rationalize the energy consumption and to reduce the environmental pollution associated with tractors and farm machinery use in the Egyptian farms. The engine performance characteristics were deduced as affected by the mixture conditions(the time of fuel and oxygen injection), the prechamber volume (volume ratio), compression ratios, Fuel type (Gasoline \Propan) and engine Speed (1000, 1500, 2000 rpm).

The study is also focused on the effects exhaust emission on the environmental pollution

These parameters have more or less significant influence on the engine output, fuel consumption, and exhaust emission. Combustion pressure traces were recorded simultaneously. These records were analyzed to obtain the required engine performance data and to compare with a conventional spark ignition engine.

A modification of the conventional spark-ignition piston engine, the stratified charge engine is designed to reduce emissions without the need for an exhaust-gas recirculation system or catalytic converter. Its key feature is a dual combustion chamber for each cylinder, with 
a pre-chamber that receives a rich fuel-air mixture while the main chamber is charged with a very lean mixture. The spark ignites the rich mixture that in turn ignites the lean main mixture. The resulting peak temperature is low enough to inhibit the formation of nitrogen oxides, and the mean temperature is sufficiently high to limit emissions of carbon monoxide and hydrocarbon.

\section{EXPERIMENTAL METHODOLOGY}

The engine that was deduced in the present study was a Ferryman A30 marine single cylinder, variable compression ratio, watercooled engine with cylinder bore and stroke of 82 and $95 \mathrm{~mm}$, respectively (stroke- bore ratio of 1.16). It was established at Engine Test Laboratory, Faculty of Engineering, Mansoura University. It can be operated in sequence as stratified charge, and conventional spark ignition engines. As a stratified charge

In the case of testing as stratified charge ignition engine (SCIE), it was prepared with different facilities to be performed as stratified charge engine. These facilities give variable pre-chamber volume, variable ignition timing, variable pr-chamber injection timing and different fuel type injection in the pre-chamber. A schematic diagram of the experimental apparatus and the stratified charge divided-chamber are shown in Figs. (1) and (2), respectively.

As indicated from Fig.(1), the tested engine was equipped with standard experimental apparatus to measure and determine the rate of fuel consumption ( $\mathrm{FC}$ in $\mathrm{g} / \mathrm{h}$ ) and the corresponding brake horsepower(BHP in $\mathrm{KW}$ ). That in turns enabled to determine the specific fuel consumptions (SFC) as follows:-

$S F C=\frac{\mathrm{FC}(\mathrm{g} / \mathrm{h})}{\mathrm{BHP}(\mathrm{KW})} \ldots \ldots \ldots . .(g / k w . h)$

The equipped apparatus were also able to measure and determine specific nitric oxide (SNO) and the unburned hydrocarbon (SHC) that emitted from the exhaust products. The (SNO) and the (SHC) were directly amounted in $\mathrm{gr} / \mathrm{KW}$.h by means of a exhaust gas analyzer. The technical specifications of that analyzer are listed in table (1), while the its function overview and photo are shown in figs $3 \mathrm{a}$ and $3 \mathrm{~b}$ respectively . 


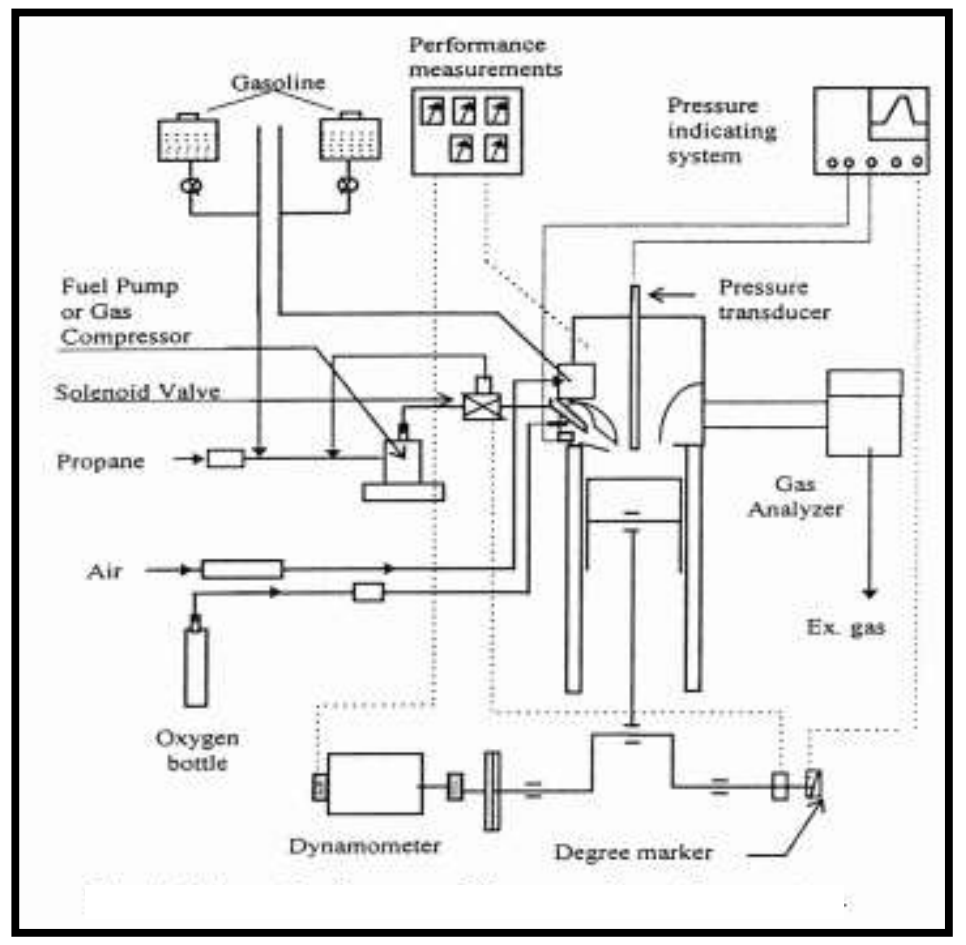

Fig.(1): Schematic diagram of the

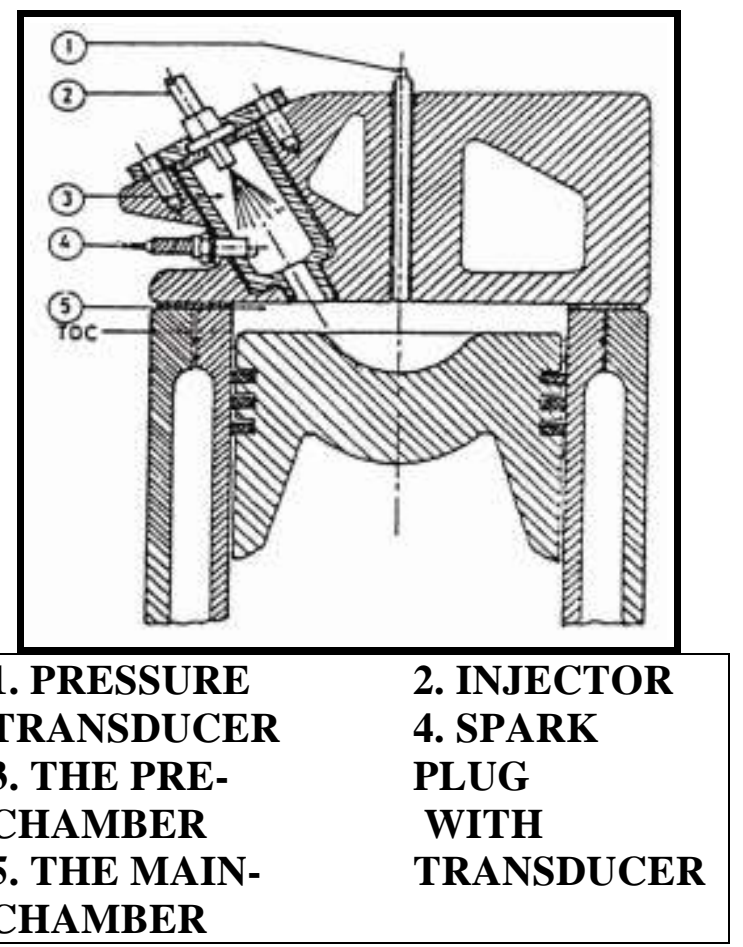

Fig. (2): Schematic diagram of the stratified charge divided chamber. 

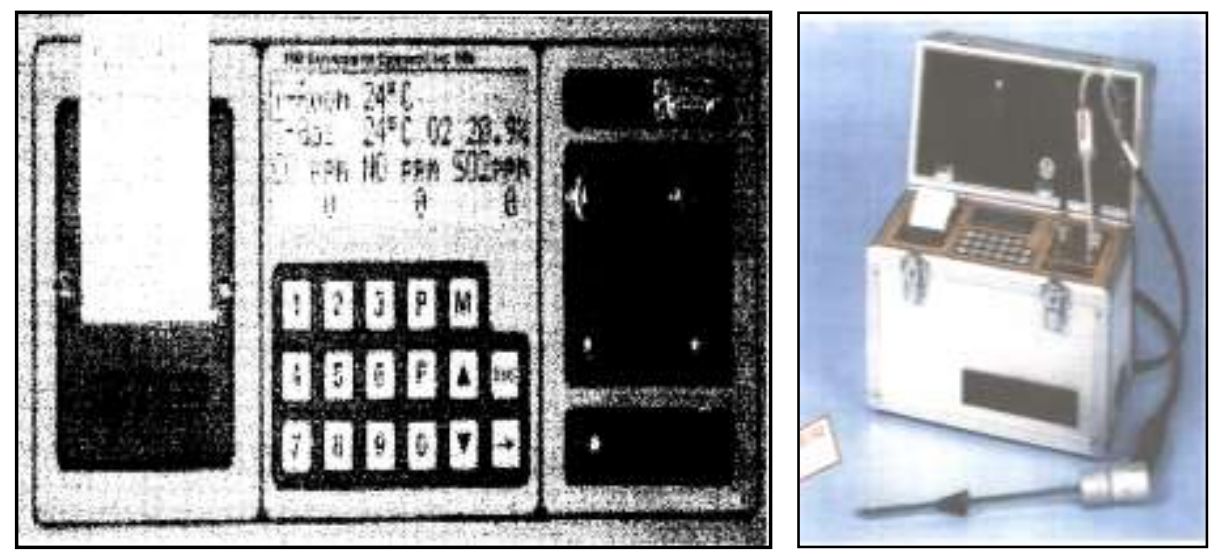

(3a) The overview

Fig.3 : The analyzer.

Table 1: The technical specifications of that analyzer

\begin{tabular}{|c|c|}
\hline \multicolumn{2}{|l|}{ Specifications } \\
\hline $\begin{array}{l}\text { Power Inlet } \\
\text { Battery } \\
\text { Display } \\
\text { Operating } \\
\text { temperature. } \\
\text { Calibration. } \\
\text { Printer. }\end{array}$ & $\begin{array}{l}\text { 110VAC/60Hz or } \\
230 \mathrm{VAC} / 50 \mathrm{~Hz} \text {. } \\
\text { Sealed lead acid 12VDC. } \\
\text { 4-line,20-chamber illuminated } \\
\text { LCD. } \\
\text { 50F- } 104 \mathrm{~F} / 10 \mathrm{C}-40 \mathrm{C} \\
\text { Automatic. } \\
\text { Thermal printer-paper width } \\
\text { 58mm. }\end{array}$ \\
\hline \multicolumn{2}{|l|}{ Function overview } \\
\hline Measurements & Calculations \\
\hline $\begin{array}{l}\text { Gas temperature. } \\
\text { Ambient } \\
\text { temperature. } \\
\mathrm{O}_{2} \\
\mathrm{CO}, \mathrm{NO}, \mathrm{SO}_{2}, \mathrm{NO}_{2}, \mathrm{HC}\end{array}$ & $\begin{array}{l}\mathrm{CO}_{2} \\
\text { losses } \\
\text { Excess air } \\
\mathrm{NO}_{x}\left(\mathrm{NO}+\mathrm{NO}_{2}\right)\end{array}$ \\
\hline
\end{tabular}

The engine tests were deduced under numerous variables for both tested engines The variables of the stratified charge spark ignition engine (SCIE), included two different injected fuel types (gasoline 
and propane) in the pre-chamber followed by an injection of oxygen with each fuel type the volume ratio(VR) (as a function of the prechamber volume,) with investigated levels of $(5,10,15,20)$, compression and charge volume ratio, degree of charge stratification, engine speeds, and the time injection. While, the variables of the conventional engines(CIE) included two degrees of charge stratification(1.2 and 1.6), and the time of fuel and oxygen injection upon the engine performance and combustion characteristics at different compression ratios of and corresponding engine speeds of 1000,1500,2000rpm.

Tests were run on a modified Ferryman A30 marine single cylinder, variable compression ratio, water-cooled engine with cylinder bore and stroke of 82 and $95 \mathrm{~mm}$, respectively (stroke- bore ratio of 1.16) .

Engine out put power was measured with an electric dynamometer. Pressures were recorded by AVL and E32 pizoquaz-electric indicators pressure pickup units located in the pre-chamber and main-chamber, respectively and a degree marker system was used to record the crank-angle degrees. Gasoline, propane and oxygen were injected separately in the pre-chamber. Gasoline was injected by an injection pump through an injector and propane was injected by a gas compressor through a nozzle, and oxygen was injected directly from an oxygen bottle through a nozzle into the prechamber. Each injection system was equipped with a control system for injection pressure and timing, and devices for measuring fuel or oxygen consumption.

\section{RESULTS AND DISCUSSION}

The obtained experimental results were classified in order to study effects of pre-chamber volume to the total clearance volume which defined as volume ratio (VR), timing of fuel injected in the prechamber. The ratio of the pre-chamber propane at two degrees of stratification is shown in Fig. 3. Generally, volume ratio affects engine brake specific fuel consumption for all considered speeds and degrees of stratification. Values of brake specific fuel 
consumption decrease with increasing volume ratio until about $10 \%$. This is may be, due to the incomplete oxidation of the fuel in the rich region of the charge with subsequent loss in the mean effective pressure.

equivalence to the main-chamber equivalence ratio at the time of ignition which defined as degree of stratification (S) and compression ratio (CR). Also, comparison between results of standard engine and stratified charge engine has been carried out.

\section{Effect of Volume Ratio(VR)}

Effect of volume ratio on brake specific fuel consumption for different speeds and injection of gasoline and propane at two degrees of stratification is shown in Fig. 3.

Generally, volume ratio affects engine brake specific fuel consumption for all considered speeds and degrees of stratification. Values of brake specific fuel consumption decrease with increasing volume ratio until about $10 \%$. This is may be, due to the incomplete oxidation of the fuel in the rich region of the charge with subsequent loss in the mean effective pressure.

Fig. 3. Effect of volume ratio on specific fuel consumption for injection of gasoline and propane at different speeds. It can be seen that at the average effect of Volume Ratio, the reduction \% of SFC due to speed increasing were 8.7, and 9.94 for using Gasoline, and Propane respectively.

Effect of the volume ratio on the emission of nitric oxide and unburned hydrocarbon is shown in Figs.4 and 5, respectively- As shown in Fig. 4, the brake specific nitric oxide (BSNO) decreases as volume ratio increased initially and goes through a minimum at VR $8-10 \%$.

Also, the same trend of the effect of volume ratio on brake specific unburned hydrocarbon (BSHC) can be shown in Fig. 5.

However, the BSHC remarkably increased for volume ratio larger than $10 \%$. This leads to lower adiabatic flame temperature in the main-chamber than that in the pre-chamber 

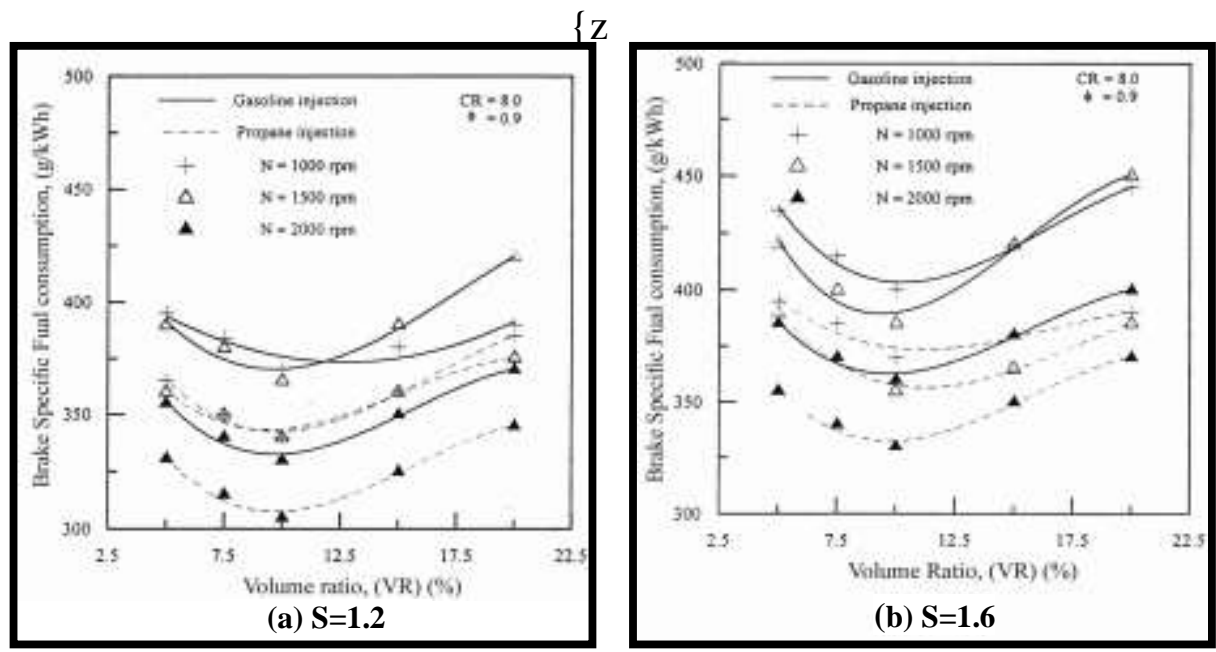

Fig. (3): Effect of volume ratio on brake specific fuel consumption for different speeds and injection fuels at different degree of stratification.

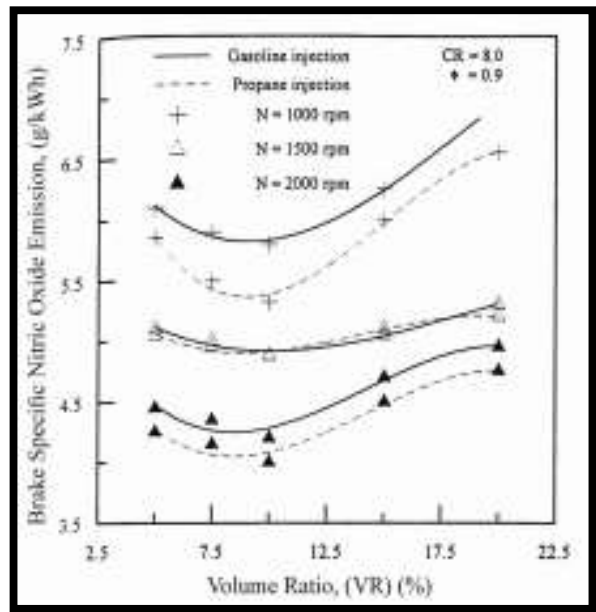

Fig.(4): Effect of volume ratio on brake specific nitric oxide emission (BSNO)for different speeds and injection fuels at degree of stratification 1.2 .

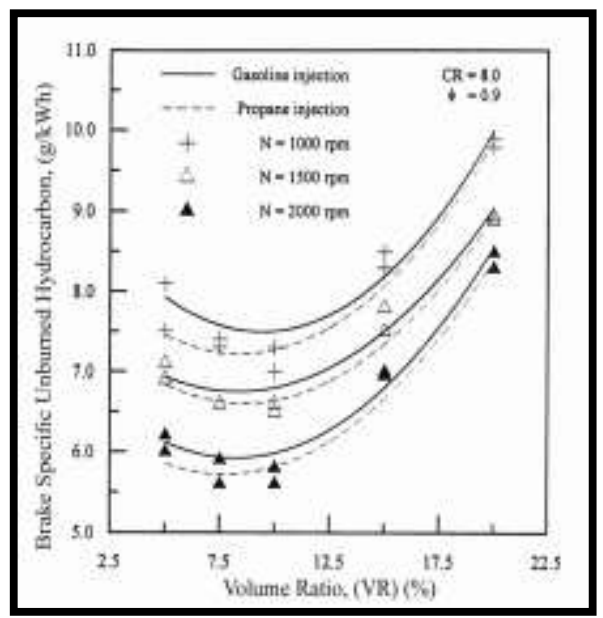

Fig. (5): Effect of volume ratio on brake specific unburned hydrocarbon emission (BSHC) for different speeds and injection fuels at degree of stratification 1.2.

\section{Effect of Injection Time}

The effect of start injection of fuel in the pre-chamber on the thermal efficiency is shown in Fig. 6. From this figure it can be seen that the start of fuel injection in the pre-chamber has an influence on 
the engine performance. The optimum start of fuel injection is varied from $40 \sim 60$ degrees BTDC for all ranges of the equivalence ratio.
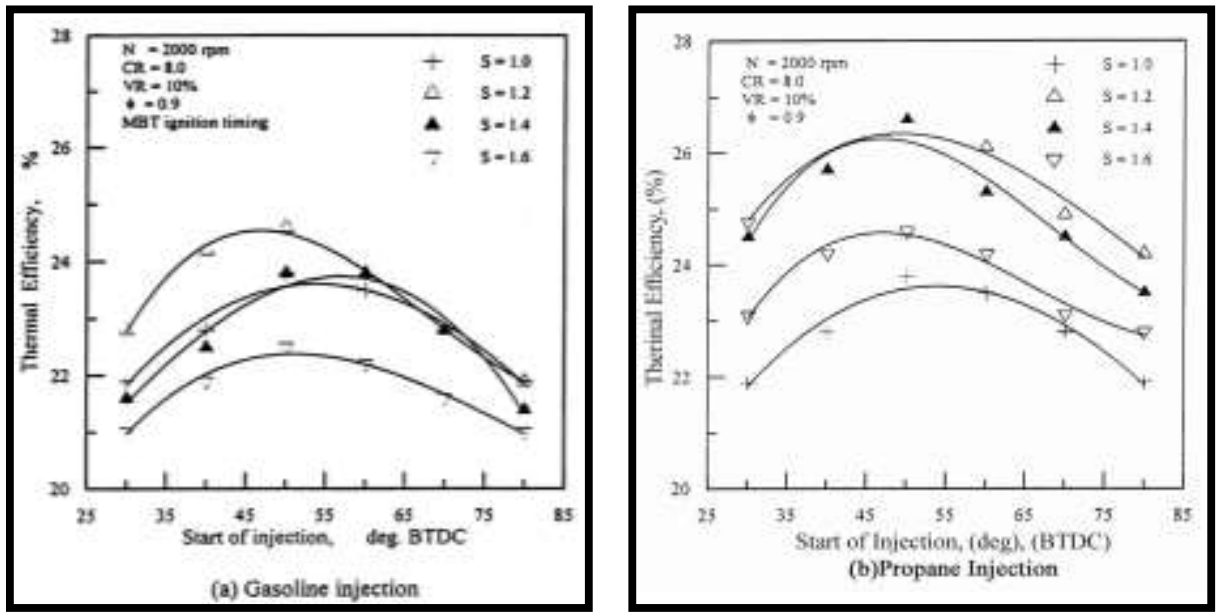

Fig. (6): Thermal Efficiency Versus Start of Fuel Injection for Different Degrees of Stratification.

\section{Effect of Degree of Stratification:}

Effects of the degree of stratification on engine performance and emission characteristics for different equivalence ratios, and two engine speeds at optimum value of compression ratio, volume ratio and MBT ignition timing are shown in Figs. 7-9.

From Fig. 7, it can be seen that the brake power is increased with stratification degree until $\mathrm{S}=1.2$ to 1.4 , and then tends to decrease. The rate of increasing of brake power for propane fuel injection is higher than for gasoline injection due to the higher heat of reaction for propane than gasoline.

The effect of the degree of stratification on brake specific nitric oxide (BSNO) emissions level is shown in fig.9 BSNO emission curves show lower values for any increase in degree of stratification Also, it is found that the effect of stratification on BSNO level is remarkably dependent on the overall equivalence ratio .The lower BSNO values were obtained with leaner mixtures .It is useful for understanding the dependence of $\mathrm{NO}$ formation upon stratification 
to review the kinetic theory of $\mathrm{NO}$ formation and the trials made to extend it to accounts for charge stratification.
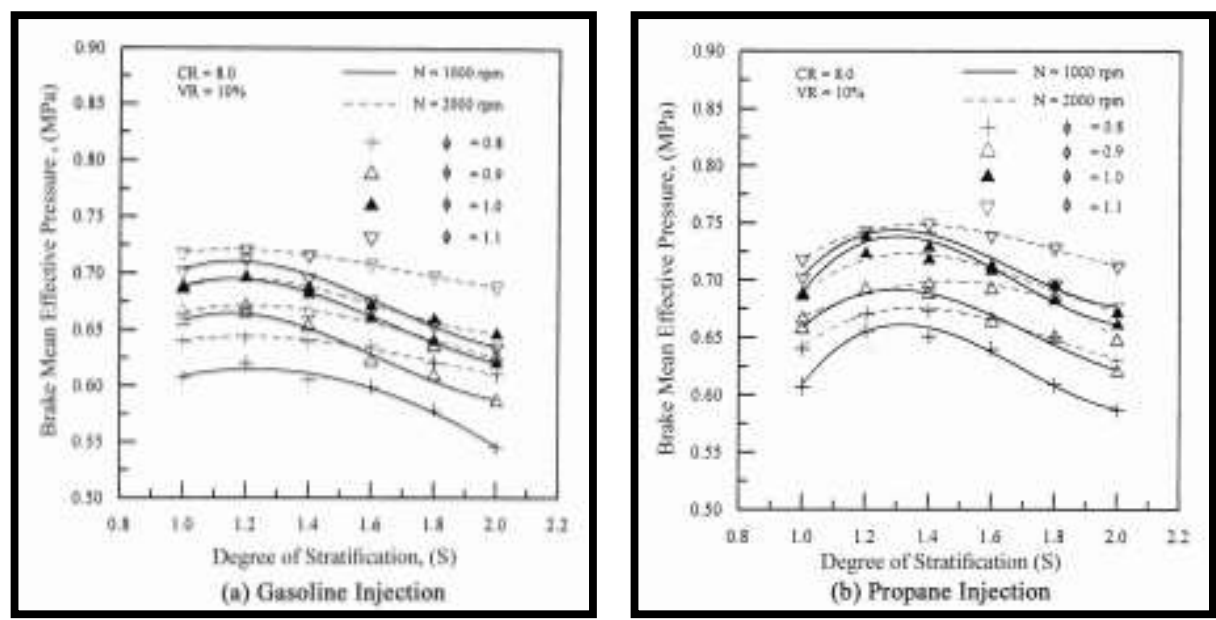

Fig. (7): Effect of degree of stratification on brake mean effective pressure

for different equivalence ratios.
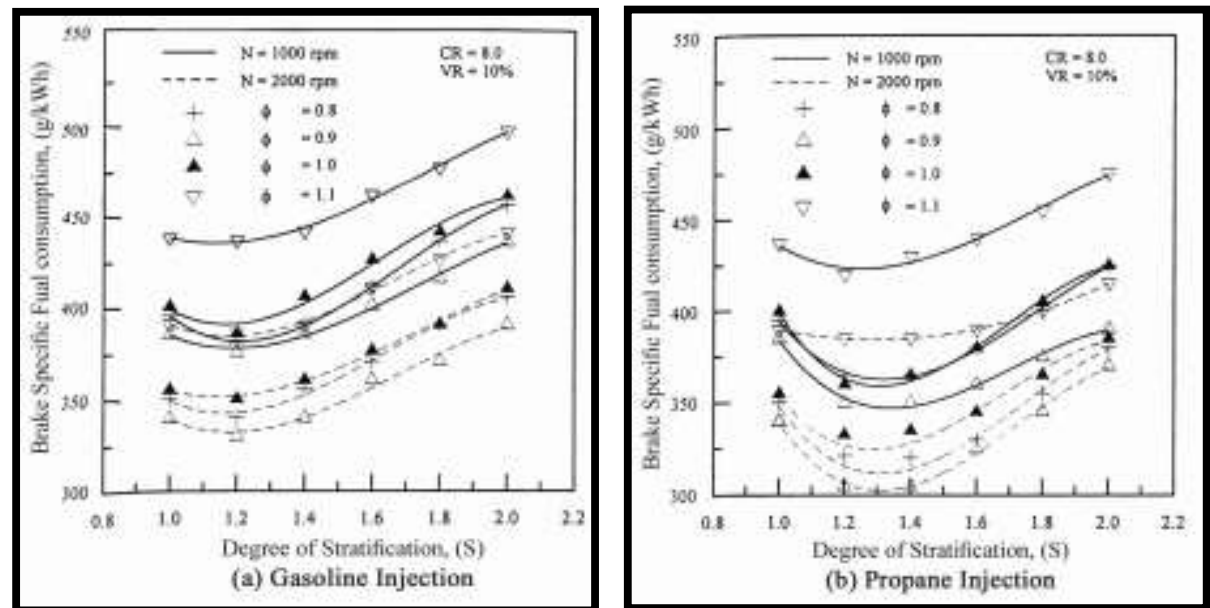

Fig. (8): Effect of degree of stratification on brake specific fuel consumption for different equivalence ratios at different engine speeds. 

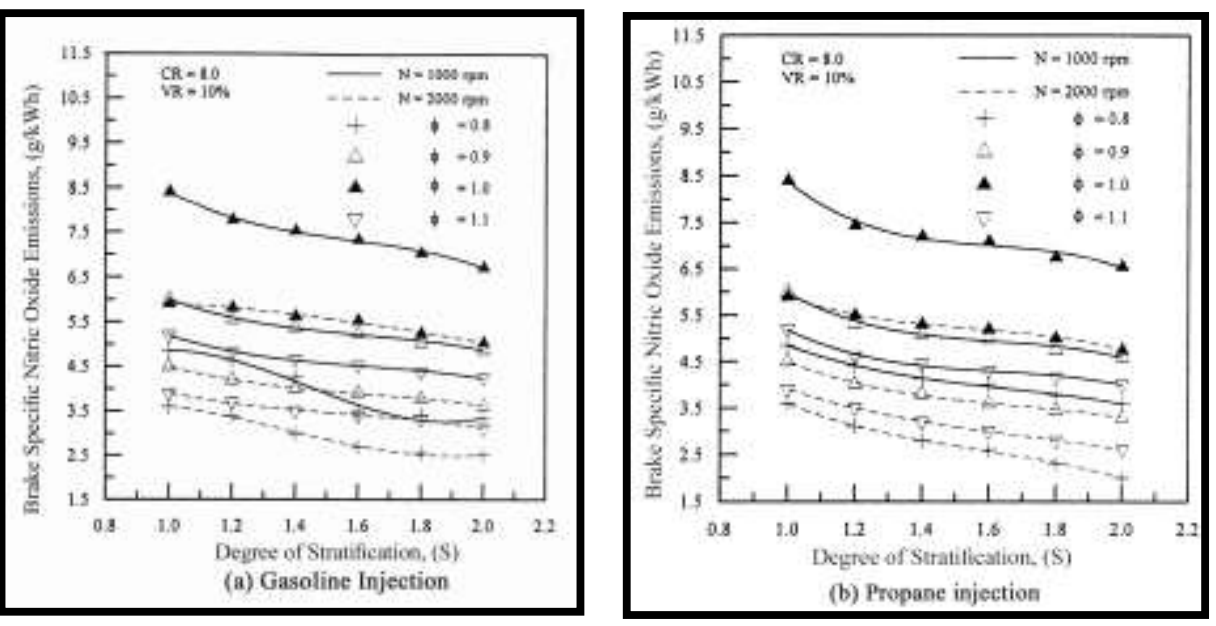

Fig. (9): Effect of degree of stratification on brake specific nitric oxide emissions for different equivalence ratios at different engine speeds.

\section{Effect of Compression Ratio:}

The effect of compression ratio on brake mean effective pressure (BMEP) is shown in Fig. 10. For stratified charge engine, the BMEP increases as the compression ratio is increased. However, for divided chamber without stratification $(S=1.0)$, it can be seen that the brake mean effective pressure increases with increasing the compression ratio up to the knock limit, after which it drops with any further increase in compression ratio.

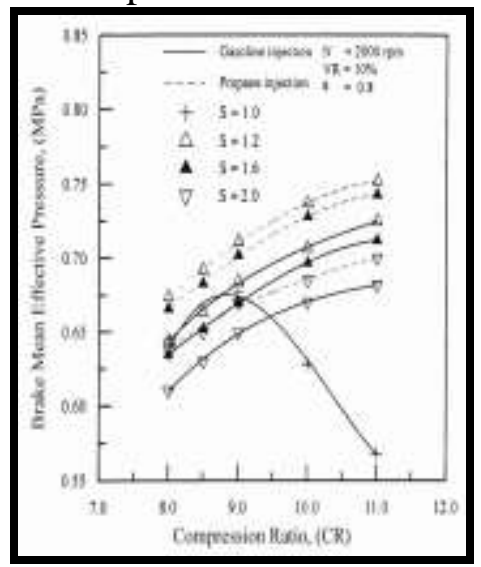

Fig. (10): Effect of compression ratio on brake mean effective pressure for different degree of stratification. 


\section{Comparison between Standard Engine and Stratified Charge}

\section{Engine}

Comparison of BSFC of the stratified charge test engine and the standard engine operating homogeneously before modification is shown in Fig. 11. Six engine operating cases have been shown in the illustrated figure as follows:

Case 1 : Single chamber-homogeneous (standard).

Case 2 : Divided chamber-homogeneous (non-stratified, $S=1.0$ ).

Case 3 : Divided chamber-stratified charge with gasoline injection $(\mathrm{S}=1.2)$.

Case 4 : Divided chamber-stratified charge with propane injection $(\mathrm{S}=1.2)$.

Case 5 : Divided chamber-stratified charge with gasoline and oxygen injection

$$
(\mathrm{S}=1.2) \text {. }
$$

Case 6 : Divided chamber-stratified charge with propane and oxygen injection $(\mathrm{S}=1.2)$.

As shown in Fig. 11 there is a decrease in the specific fuel consumption associated with the presence of divided chamber in the region which overall equivalence ratio less than stoichometric.

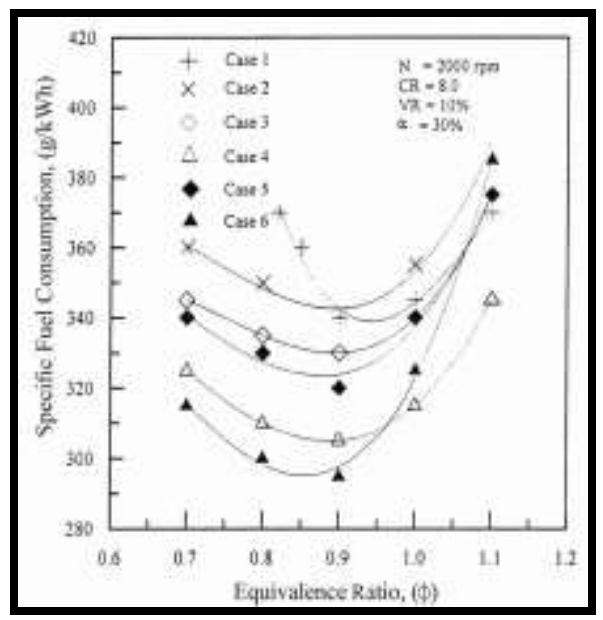

Fig. (11): Comparison of brake specific fuel consumption between standard and stratified charge engine. 
With increase of oxygen concentration (a) to $30 \%$ in the used air there is a decrease in the specific fuel consumption for all range of overall equivalence ratio. This is may be due to that oxygen injection enhancing the combustion characteristics and reducing the residual gases in the pre-chamber.

Comparison of lean misfire limit (LML) for different engine conditions is shown in Fig. 12. The lean misfire limit is defined eventually as the point reached where engine operation becomes rough and unstable, and hydrocarbon emissions increases rapidly. Also this figure indicates that the stratified charge engine was found to have the ability to operate leaner than the standard engine. The turbulence at the active products emerging from the pre-chamber serves as a more effective ignition source for the main-chamber mixture.

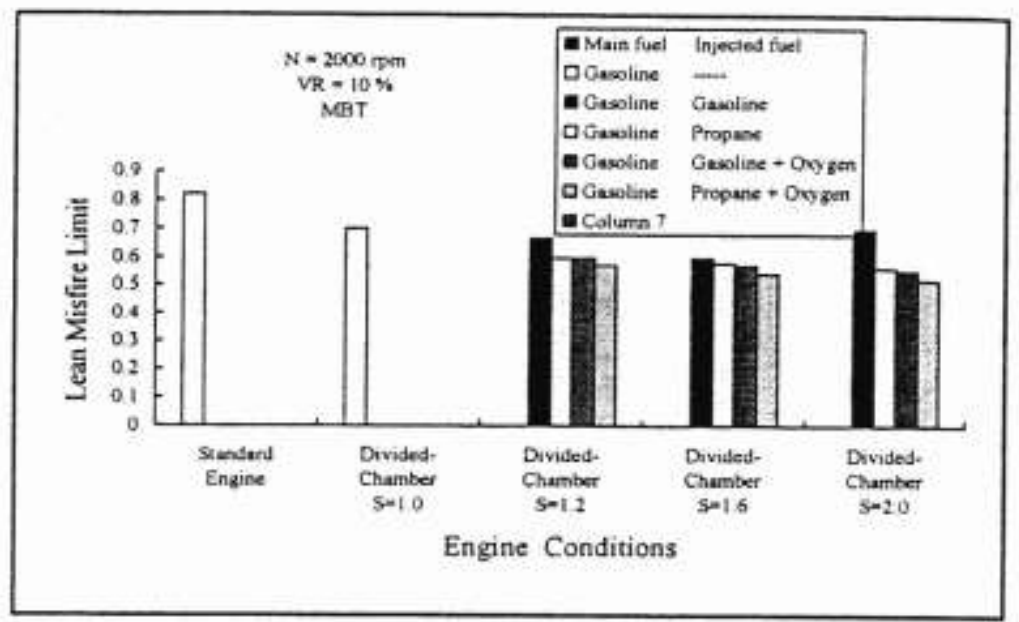

Fig. (12): Comparison of lean misfire limit (LML) for engine conditions.

\section{CONCLUSION}

Based on the obtained results, the following conclusions may be drawn:

1. Generally, the brake power of the engine is gradually increased 
with stratification until $\mathrm{S}=1.2-1.4$ and then decreased.

2. The optimum volume ratio is in the range of $10 \%$.

3. Fuel injection not start too early during compression and should not terminate too close to the end of compression. From the results an optimum values were found between 40 and 60 degrees BTDC.

4. The brack specific fuel consumption (BSFC) was decreased with stratified engine in the lean region than standard engine, and the decreasing rate is higher for all overall equivalence ratio with propane injection.

5. Charge stratification yields reduction in NO emissions in the range of overall equivalence ratios.

6. Injection of oxygen in the beginning of compression stroke enhances the engine performance and Combustion characteristics.

7. Stratified charge engines can be operated by injecting different fuels at high compression ratios without Combustion problems which inturn leads to increasing the thermal efficiency

8. Stratified charge engines can be operated at lean mixture until an equivalence ratio of 0.55 , which couldn't be achieved with the conventional engines. The operation with lean mixture leads to the decrease of NO concentration emitted with the exhaust products.

\section{REFERENCES}

1. Choi, S. B., and Hedrick, J. K., 2000, “ Based Controller Design Method for Improving Air/Fuel Characteristics of Spark Ignition Engines," IEEE Trans. Control Syst. Technol., 6(3), pp. 325-334.

2. Grizzle.J.W,Julia Buckland and Jing Sun(2001),"Idle speed control of a Direct Injection Spark Ignition Stratified charge Engine "Control Systems Laboratory, Electrical Engineering and Computer Science Department, University of Michigan, Ann Arbor, MI 48109-2122, U.S.A. 
3. Manzie, C., Palaniswami, M., and Watson, H., 2001, "Gaussian Networks for Fuel Injection Control," Proc. Inst. Mech. Eng., Part D(J. Automob. Eng.), 215(10), pp. 1053-1068.

4. Manzie, C., Palaniswami, M., Ralph, D., Watson, H., and Yi, X., 2002, "Model Predictive Control of a Fuel Injection System With a Radial Basis Function Network Observer," ASME J. Dyn. Syst. Meas. Control, 124(4), pp. 648- 658.

5. Nakazono, T. ( 1994) "Study of Lean Burn Gas Engine" JSME, vol. 37 , no. 3 .

6. Nakazono, T. and Natsume, Y. ( 1994) "Effect of Dimensions of Pre- chamber on Lean Burn Gas Engine" JSME, vol. 37, no. 4.

الملخص العربيى

"الطاقة المستهلكة والتلوث البيئى للمحرك المشحن تطابقيا والمحرك التوك

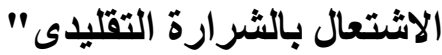

حمدى محمد نور

تهدف الجهود التي تبذل لتطوير محركات الاشعال بالثر ارة إلى الحد من نو اتج الاحتراق

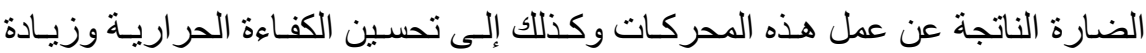

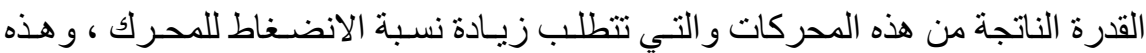

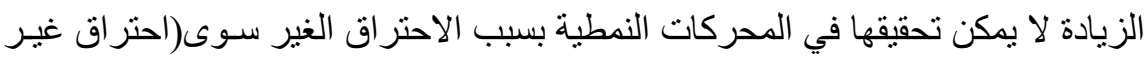

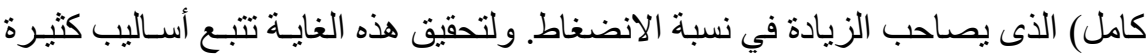

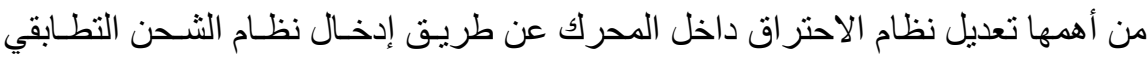

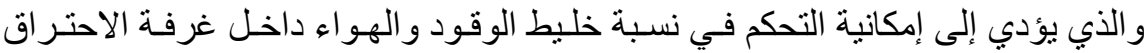
وبالتالي تحقيق الاحتر اق السوى و الكالية الكامل.

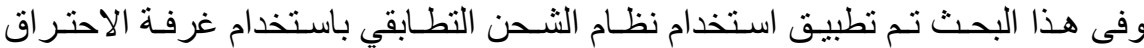
المقسمة إلى غرفة رئيسية وأخرى أولية حيث يتم تغذية الغرفة الأولية بخليط غني نسي نسبياً

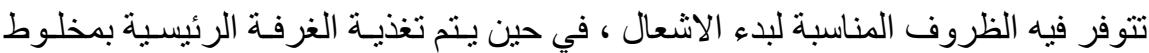

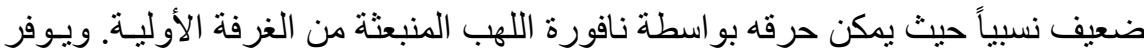

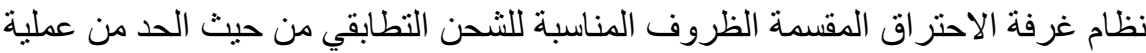

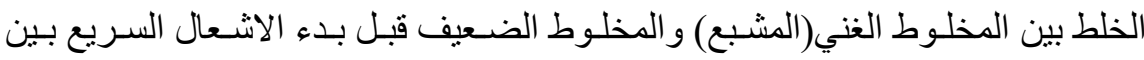
المخلوطين أثناء عملية الاحتر اق وبدء مشوار التمدد.

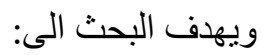


ا ـ اجر اء دراسة عمليه عن أداء وخصائص الاحتر اق لمحرك إثعال بالشر ارة ذو غرفة

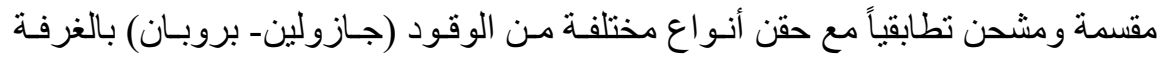

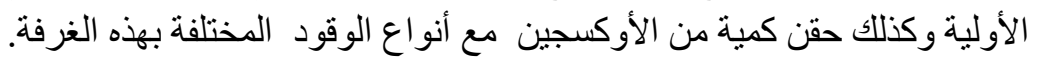

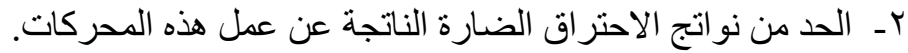

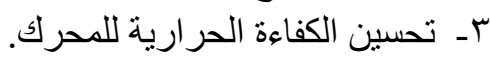

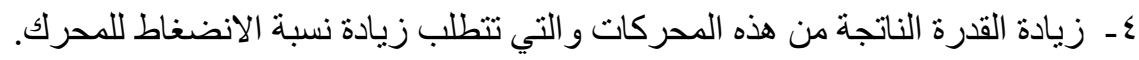

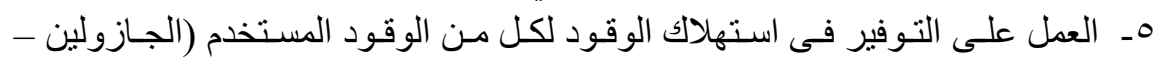

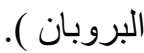

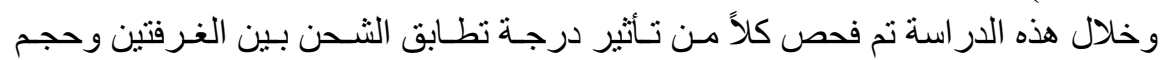

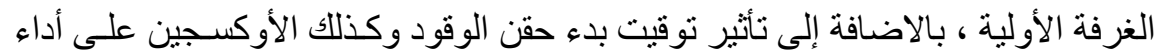

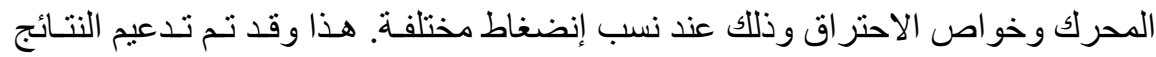

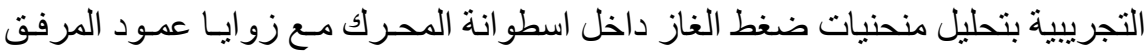

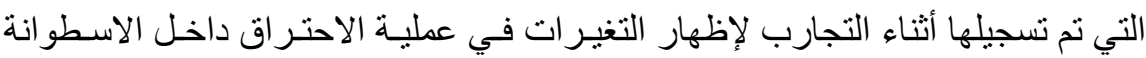

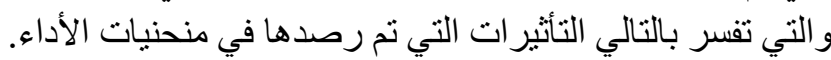

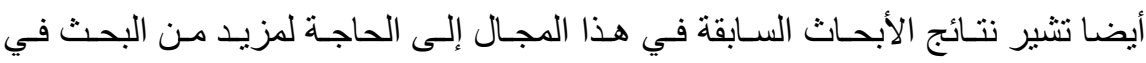

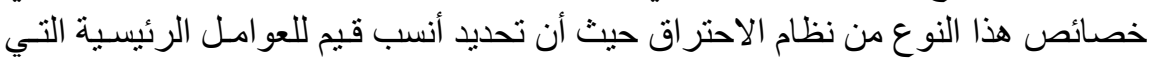

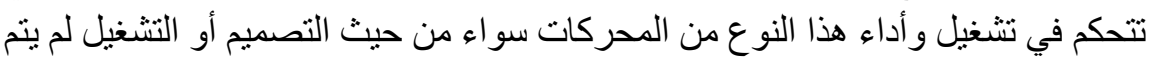

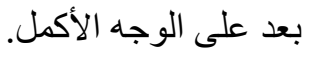

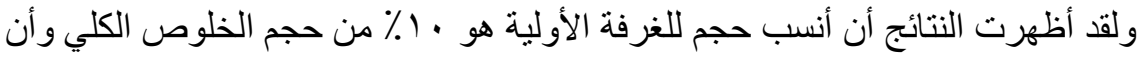

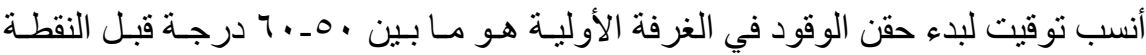

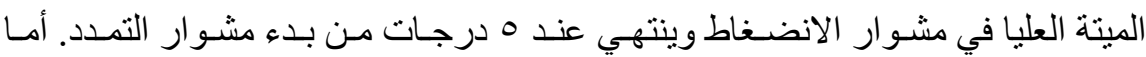

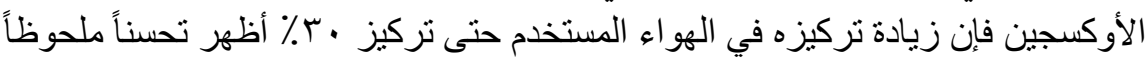

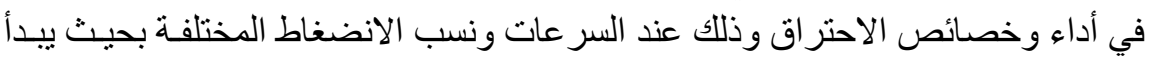

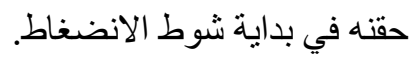

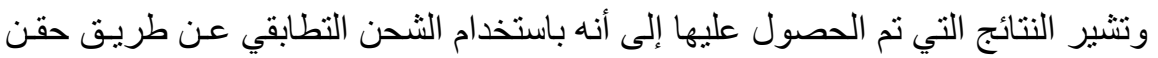

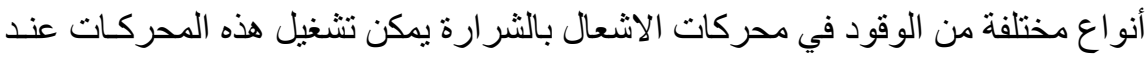

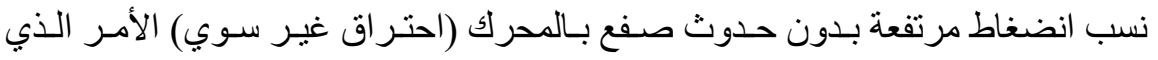

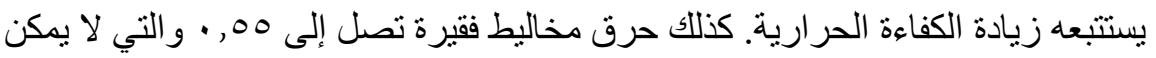

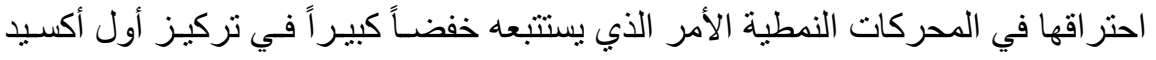

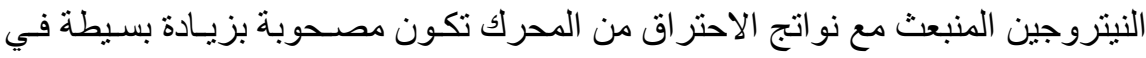

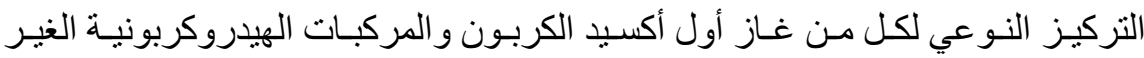

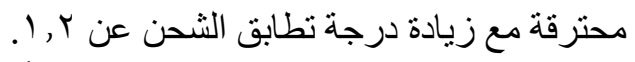

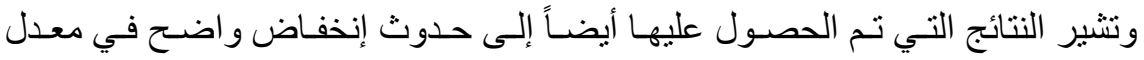

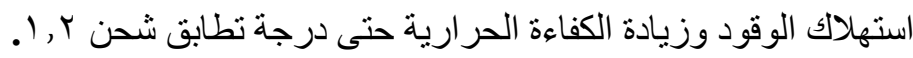

